\title{
CHARACTERIZATION OF GLUCOMANNAN FROM AMORPHOPHALLUS PANOMENSIS IN VIETNAM
}

\author{
Nguyen Tien An ${ }^{1,}$, Do Truong Thien ${ }^{2}$, Nguyen Thi Hoa ${ }^{1}$, Vu Thi Hue ${ }^{1}$, \\ Vu Thi Minh Thu ${ }^{1}$, Lai Thi Thu Trang ${ }^{1}$ \\ ${ }^{I}$ Thai Binh University of Medicine and Pharmacy, 373 Ly Bon, Thai Binh city, Vietnam \\ ${ }^{2}$ Institute of Chemistry, VAST, 18 Hoang Quoc Viet road, Hanoi, Vietnam \\ "Email: nguyentienanvhh@gmail.com
}

Received: 1 June 2015; Accepted for publication: 24 September 2015

\begin{abstract}
A glucomannan has been isolated from the tuber of Amorphophallus panomensis by a simple method without using toxic chemicals. The glucomannan content of the tuber was $4 \%$ (w/w). The structure of the glucomannan was investigated by IR and NMR spectroscopy revealing that it consists of mannose and glucose units with a mannose/glucose ratio of about $1.00 / 0.13$. The degree of crystallization was investigated by XRD diffraction revealing that the glucomannan was amorphous. The molecular weight was determined by viscosimetry to be of $1.2 \times 10^{6} \mathrm{Da}$.
\end{abstract}

Keywords: Amorphophallus panomensis, glucomannan, konjac.

\section{INTRODUCTION}

Amorphophallus $s p$. is a perennial herbaceous herb. It grows in mountain or hilly areas in subtropical regions mainly in the South East of Asia. It has been used as food and food additives in China and Japan for more than 1000 years. Glucomannan (GM) is a polysaccharide of the mannan family, very abundant in nature, specifically in softwoods (hemicellulose), roots, tubers and many plants bulbs. Despite the variety of sources, the most commonly used type of GM is named Konjac glucomannan (KGM), which is extracted from tubers of Amorphophallus plants. Irrespective of its origin, GM is composed of $\beta$-1,4-linked D-mannose and D-glucose monomers. However, the mannose/glucose monomer ratio may vary depending on the original source of GM. For example, it has been reported that Konjac GM has a molar ratio of around 1.6:1, whereas GMs extracted from Scotch pine and orchid tubers have ratios of 2.1:1 and 3.6:1, respectively. These values should be regarded cautiously given the variability observed depending on the studies and, in particular, on the analytical procedures [1,2].

Studies on glucomannan showed that it has many applications in many fields. Due to its biogradablility and gel-forming ability, konjac glucomannan can be widely used for drug delivery such as capsule for chronic stomach disease. Wang et al. reported that a kind of alginate-konjac glucomannan-chitosan beads could be used as controlled release matrix [3]. 
Glucomannan has very good film-forming ability so several kinds of transparent blend films of konjac glucomannan with polyacrylamide, gelatin, sodium carboxymethylcellulose, polyvinyl pyrrolidone, chitosan, sodium alginate and cellulose, were invented $[4,5]$. The occurrence of intra- and intermolecular interaction of the pure components, as well as the intermolecular interactions between KGM and these substance come from hydrogen bond formation. $\mathrm{Li}$ et al also reported a kind of edible membrane material made from the mixture of konjac glucomannan and xanthan, which showed better strength and water-resistance than konjac glucomannan itself [6]. In the patent of Yang et al coating materials containing konjac glucomannan were invented for preserving fresh produce (e.g. apples). The coating composition was effective to control respiratory exchange, i.e. the passage of gases, particularly oxygen, ethylene, carbon dioxide and water vapor, into and out of the produce, thereby controlling maturation and ripening of the produce [7].

In the field of cosmetics, Omura et al invented a hair composition containing glucomannan and/or keratose quaternary ammonium derivatives which provided excellent conditioning effect and moisture-retaining effect without causing stickiness. Some kinds of hair-styling preparations containing glucomannan with less stickness and giving natural gloss and smoothness to hair. Some kinds of cosmetic oil-in-water emulsions containing konjac glucomannan were also invented [8]. Takada invented a kind of water-insoluble glucomannan gel particles as mild scrubbing agents for cosmetics. The dried gel particles did not damage the skin and tooth surface. Therefore they were effective as scrubbing agents [9].

Besides the applications mentioned above, konjac glucomannan and its derivatives were also used in many other areas: they can be used as biodegradable resin compositions, soil modifier, soil amendment [9]. In addition, konjac glucomannan powder can be mixed with powdery or granular charcoal and water and press-molded to charcoal shaped products having excellent properties in dehumidification, deodorization, sound absorption, and electromagnetic shielding and are suitable for water treatment, health products (such as using glucomannan to lower blood cholesterol and sugar level, help weight loss, promote intestinal activity and immune function etc) [10].

Being a member of the Araceae (arum) family, Amorphophallus panomensis was expected to contain polysaccharide, usually named glucomannan, with mannose and glucose units. Therefore, the aim of this work was to perform isolation and characterization (using FTIR, NMR, X-Ray) of polysaccharide from Amorphophallus panomensis. The polysaccharide obtained is intended to be used in food, as film-forming material, for packaging or encapsulating of pharmaceutical and biomedical products, and for designing new drug carriers.

\section{EXPERIMENTAL}

\subsection{Materials}

Tubers of Amorphophallus panomensis were collected from hilly area of Lang Son province of Vietnam. All other chemicals and reagents used were of analytical grade.

\subsection{Isolation and purification of polysaccharide from Amorphophallus tuber}

Polysaccharide from the tuber of Amorphophallus panomensis was extracted and purified as follows: Amorphophallus tubers were sliced to about $8-10 \mathrm{~mm}$ in thickness, then pulverized by a mill. The crude flour was dispersed in distilled water and laid for $3 \mathrm{~h}$, the white powder 
(glucomannan) at the bottom was separated and then washed many times with water. Then the powder was dried at $50{ }^{\circ} \mathrm{C}$ and used for further characterization. The glucomannan content (GF) was calculated using the following formular: GF\% $=\left(\mathrm{m}_{1} / \mathrm{m}_{2}\right) \times 100 \%$ with $\mathrm{m}_{1}$ and $\mathrm{m}_{2}$ were weight of final white powder and original Amorphophallus tubers, respectively.

\subsection{Characterization of polysaccharide}

FTIR spectrum of the glucomannan was recorded on the FTIR-Impact 410 spectrometer in the range between 4000 and $400 \mathrm{~cm}^{-1} .{ }^{1} \mathrm{H}-\mathrm{NMR}$ and ${ }^{13} \mathrm{C}$-NMR spectra were recorded on the 500 $\mathrm{MHz}$ Bruker Avance spectrometer, the sample concentrations being about $5 \mathrm{~g} / \mathrm{l}$ and $20 \mathrm{~g} / \mathrm{l}$, respectively, in $0.5 \mathrm{~N} \mathrm{NaOH} / \mathrm{D}_{2} \mathrm{O}$ at $353{ }^{\circ} \mathrm{K}$.

The intrinsic viscosity of glucomannan was measured by Ubbelohde viscometer according to method of $\mathrm{Li}$ et al. Mark-Houwink parameters were fixed according to $\eta=5.96 \times 10^{-2} \times \mathrm{M}_{\mathrm{v}}^{0.7317}[6]$.

X-ray diffraction pattern was analyzed using a Siemens D5000 (Japan) diffractometer equipped with a $\mathrm{CuK}_{\alpha}$ target at $40 \mathrm{kV}$ and $30 \mathrm{~mA}$ with a scan rate of $4 \% \mathrm{~min}$. The diffraction angle ranged from $2 \theta=5^{\circ}$ to $2 \theta=65^{\circ}$.

\section{RESULTS AND DISCUSSION}

\subsection{Isolation of polysaccharide from Amorphophallus tuber}

In recent years, there were many studies on glucomannan and its applications. The isolation and purification of glucomannan from Amorphophallus plants was one of the most important part of these studies. According to traditional methods, the isolation and purification process were often carried out with dried Amorphophallus tubers [5]. However, in our process, glucomannan could be directly obtained by dispersion of the crude flour in water because of its low solubility and high density. In this process, the fat and protein were dissolved by water. The glucomannan content was about $4 \%$ of original tuber. Thus, this glucomannan could be easily isolated from Amorphophallus tubers without using toxic chemicals. The molecular weight of glucomannan measured according to method of Li et al. was about $1.2 \times 10^{6} \mathrm{Da}$.

\subsection{FTIR analysis}

The FTIR spectrum of glucomannan in the wavelength range of $4000 \div 400 \mathrm{~cm}^{-1}$ is shown in Fig.1.

In the spectrum, the wide band observed at $3000-3700 \mathrm{~cm}^{-1}$ could be attributed to $\mathrm{O}-\mathrm{H}$ stretching. The band at $2926 \mathrm{~cm}^{-1}$ was attributed to the asymmetric stretching of C-H, while the band at $1645 \mathrm{~cm}^{-1}$ was ascribed to adsorbed water and the bands at 1426 and at $1372 \mathrm{~cm}^{-1}$ to the angular deformation of C-H. The C-O ether bond shows stretching at $1159 \mathrm{~cm}^{-1}$ while the C$\mathrm{O}$ alcohol bond shows stretching at 1082 and $1014 \mathrm{~cm}^{-1}$. Peaks from 768 to $927 \mathrm{~cm}^{-1}$ were typical for $\mathrm{C}-\mathrm{H}$ linkage of $\beta$-pyranose ring (glucose and mannose). Those results were in agreement with those of Liu et al and Jia et al. [11, 12]. 


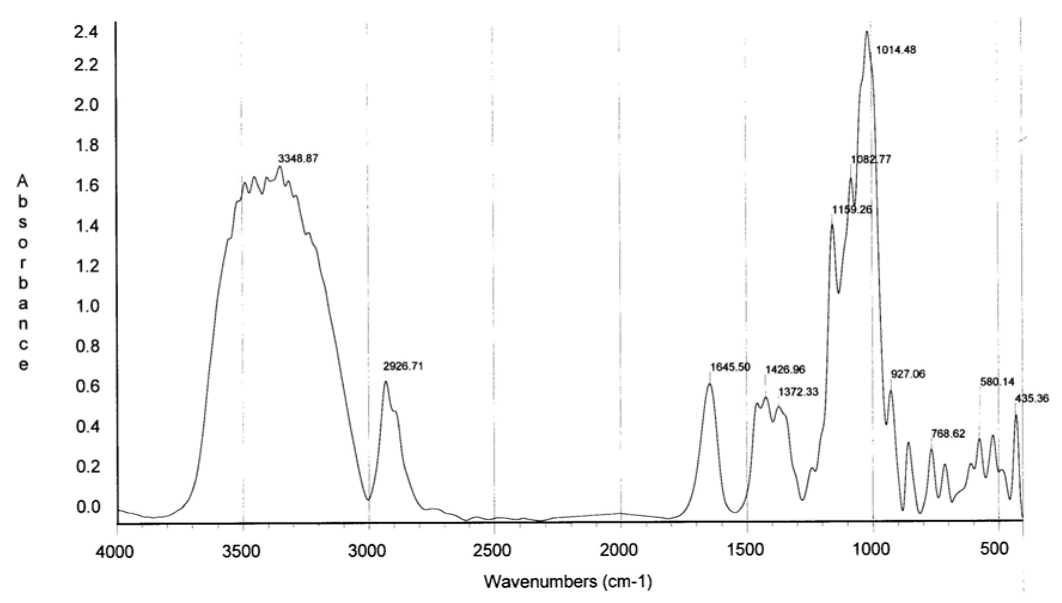

Figure 1. FTIR spectrum of panomensis glucomannan.

\subsection{NMR spectroscopy}

The ${ }^{1} \mathrm{H}-\mathrm{NMR}$ and ${ }^{13} \mathrm{C}-\mathrm{NMR}$ spectra of the glucomannan was shown in Fig. 2.

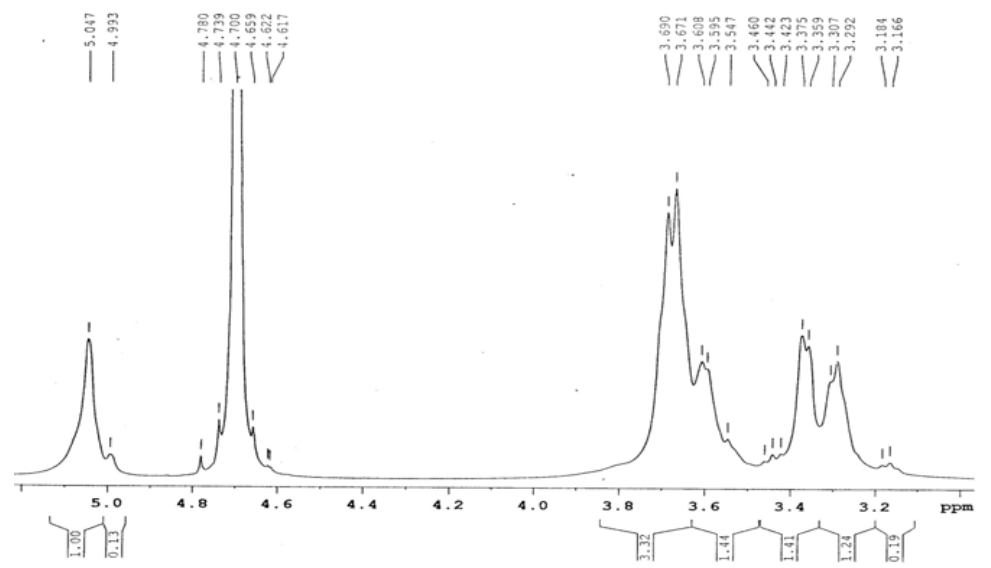

Figure 2. ${ }^{1} \mathrm{H}-\mathrm{NMR}$ spectra of panomensis glucomannan in $\mathrm{D}_{2} \mathrm{O}$ at $25^{\circ} \mathrm{C}$.

The peaks were assigned by comparison with chemical shift data reported in literature [1]. Signals were assigned as follows: H-1 of mannose $(\delta 5.047 \mathrm{ppm})$; H-1 of glucose (4.993); H-2 of both mannose and glucose (3.423 - 3.440, overlapped); H-3 of mannose (3.292) and that of glucose (3.307); H-4 of mannose (3.359) and H-4 of glucose (3.375); H-5 of mannose (3.671), $\mathrm{H}-5$ of glucose (3.690); H-6a and H-6b of mannose and glucose are (3.608), (3.442), respectively.

It could be seen from Fig. 2 that the signals attributed to hydrogens linked to C2 to C6 of both glucose and mannose units were not well separated. This was due to the complex nature of the spectra of polysaccharides. Meanwhile, the signals attributed to H-1 of both glucose unit $(4.993 \mathrm{ppm})$ and mannose unit $(5.047 \mathrm{ppm})$ were well separated. Therefore, the mannose/glucose ratio in the glucomannan molecule could be calculated using the $\mathrm{H}-1$ integrals. According to this method, the mannose/glucose ratio in the glucomannan molecule was $1.00 / 0.13$. 


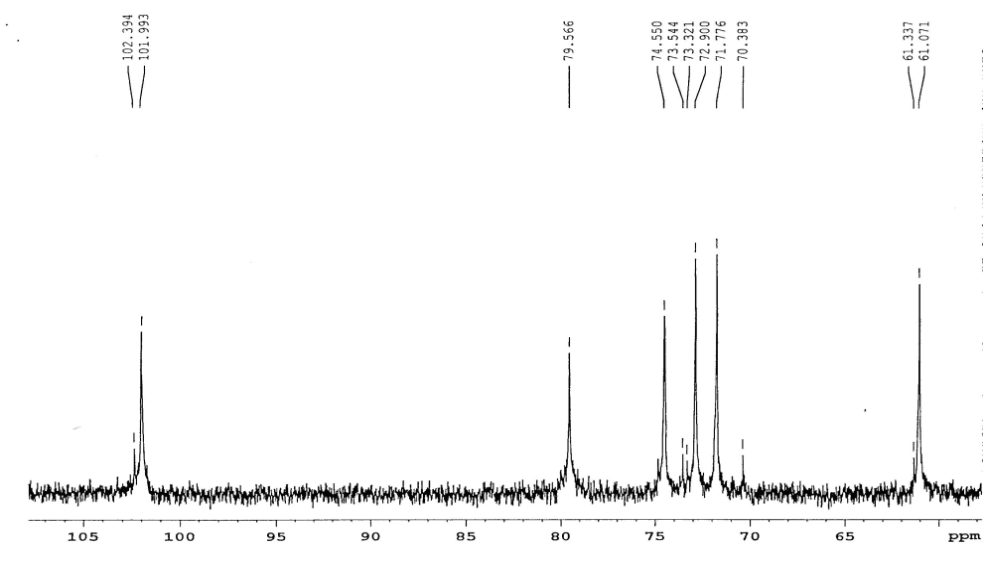

Figure $3 .{ }^{13} \mathrm{C}-\mathrm{NMR}$ spectra of panomensis glucomannan in $\mathrm{D}_{2} \mathrm{O}$ at $25^{\circ} \mathrm{C}$.

The ${ }^{13} \mathrm{C}-\mathrm{NMR}$ spectrum (Fig. 3) showed characteristic anomeric signals at $102.39 \mathrm{ppm}$ for $\beta$-D-glucose, and at $101.99 \mathrm{ppm}$ for D-mannose residues. The C-4 chemical shifts of the glucosyl and mannosyl units involved in glycosidic linkages were not separated and appeared at $79.56 \mathrm{ppm}$. The signals at $74.55,72.90$ and $71.77 \mathrm{ppm}$ were assigned to C-5, C-3 and C-2 of mannose residues, respectively. The characteristic resonances of C-5, C-3 and C-2 of $\beta-1,4-$ linked glucose residues were observed at 74.55 (overlapped with the C-5 of mannose unit), 73.54 and $73.32 \mathrm{ppm}$, respectively. The signals in the high magnetic field at 61.33 and 61.07 ppm were generated by the resonances of nonsubstituted C- 6 of glucosyl and mannosyl residues, respectively. Besides, a low intensity signal at $70.38 \mathrm{ppm}$ could be assigned to substituted C- 6 of glucosyl or mannosyl residues. Thus, the results confirmed a linear structure of glucomannan composed of 1,4-linked D-mannosyl and D-glucosyl units with a mole ratio of $1 / 0.1$ and the $\beta$ configuration of glycosidic bond in the main chain and the presence of short side chains at C-6.

\subsection{X-ray diffraction}

The X-Ray curve of panomensis glucomannan is shown in Fig. 4. As observed, the pattern of polysaccharide had both sharp peaks at $2 \theta=15^{\circ} ; 22^{\circ} ; 24^{\circ} ; 26^{\circ}$ (quite low intensity) and a very broad peak around $2 \theta=25 \div 60^{\circ}$. This results showed that the panomensis glucomannan had both amorphous and crystallized structure.

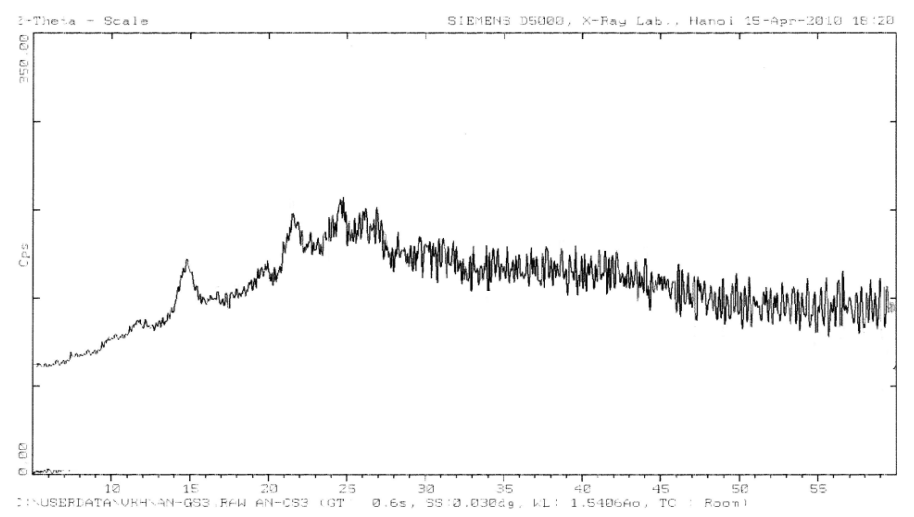

Figure 4. X-ray diffraction of panomensis glucomannan. 


\section{CONCLUSIONS}

In this study, a glucomannan was isolated in $4 \%$ yield (w/w) from tubers of the Vietnamese Amorphophallus panomensis plant by a simple method without using toxic chemicals. IR and NMR spectra indicated that the obtained panomensis glucomannan consists of $\beta$-1,4-linked D-mannosyl and D-glucosyl units with a mole ratio of 1.00/0.13. The presence of short side chains at C-6 was also observed. The molecular weight was determined by viscosimetry to be about $1.2 \times 10^{6} \mathrm{Da}$. X-ray diffraction showed that this glucomannan has both amorphous and crystallized structure.

\section{REFERENCES}

1. Ishrud O., Zahid M., Viqar U.-A., Pan. Y. - Isolation and Structure Analysis of a Glucomannan from the Seeds of Libyan Dates, J. Agric. Food Chem, 8 (2001) 37723774.

2. Gao S., Nishinari K. - Effect of deacetylation rate on gelation kinetics of konjac glucomannan, Colloids Surf. B Biointerfaces 38 (2004) 241-249.

3. Wang K., He Z. - Alginate-konjac glucomannan-chitosan beads as controlled release matrix, International Journal of Pharmaceutics 244 (2002) 117-126.

4. Yu H., Huang A., Xiao C. - Characteristics of konjac glucomannan and poly(acrylic acid) blend films for controlled drug release, J. Appl. Polym. Sci. 100 (2006) 1561-1570.

5. Ye X., Kennedy J.F., Li B., Xie B. - Condensed state structure and biocompatibility of the konjac glucomannan/chitosan blend films, J. Carbohydrate. Polymers 64 (2006) 532538.

6. Li. B., Xie. B., Kennedy. J.F. - Studies on the molecular chain morphology of Konjac glucomannan, Carbohydrate Polymers 64 (2006) 510-515.

7. Yang L., Yang X M., Petcavich R J., Mao L J. - Coating materials for preserving fresh produce, United States Patent, 6 (2001) 833.

8. Omura T., Nanba T. - Cosmetic emulsions containing alkyl-modified caroxyvinyl polymers and glucomannan, Jpn. Kokai Tokkyo Koho JP2001261525 A2, 2001-09-26 (2001).

9. Takada-Oikawa N., Katoh N., Oshida T., Kawanabe S., Kaise T. - Studies on materials containing polysaccharides as soil amendments 1: effects on animal waste water purification in a potting experiment, Journal of Material Cycles and Waste Management 2 (2000) 138-142.

10. Vuksan V., Stevenpiper J.L., Owen R., Swilley J.A., Spadafora P., Jenkins D.J.A., Vidgen E., Brighenti F., Josse R., Leiter L.A., Zheng X., Novokmet R. - Beneficial effects of viscous dietary fiber from Konjac mannan in subjects with the insulin resistance syndrome: results of a controlled metabolic trial, Diabetes Care 23 (2000) 914.

11. Liu P. Y., Zhang S. L., \& Zhang X. G. - Research and Utilization of Amorphophallus in China, Acta Botanica Yunnanica, Suppl. X, (1998) 48-61.

12. Jia C. Y. - Quantitative determination of Konjac glucomannan Content, Research and Exploitation of Natural Products 1 (1984) 42. 


\title{
TÓM TẮT
}

\section{ĐẶC TRƯNG CỦA GLUCOMANNAN TỬ CÂY NƯA THÁI (AMORPHOPHALLUS PANOMENSIS) Ở VIẸTT NAM}

\author{
Nguyễn Tiến An ${ }^{1, *}$, Đỗ Trường Thiện ${ }^{2}$, Nguyễn Thị Hoa ${ }^{1}$, Vũ Thị Huệ ${ }^{1}$, Vũ Thị Minh Thư ${ }^{1}$, \\ Lại Thị Thu Trang ${ }^{1}$ \\ ${ }^{I}$ Đại hoc Y Dươc Thái Bình, 373 Lý Bôn, Thái Bình, Việt Nam \\ ${ }^{2}$ Viện Hoá học - Viện Hàn lâm Khoa học Việt Nam, 18 Hoàng Quốc Việt, Hà Nội, Việt Nam

\section{"Email: nguyentienanvhh@gmail.com}

Bài báo này trình bày phương pháp tách glucomannan từ củ cây nưa thái (Amorphophallus panomensis) bằng phương pháp đơn giản không sử dụng các hoá chất độc hại. Hàm lượng phần trăm, cấu trúc hoá học (xác định bằng phương pháp phổ hồng ngoại và phổ cộng hưởng từ hạt nhân), mức độ kết tinh (xác định bằng phương pháp đo nhiễu xạ tia $X$ ) và khối lượng phân tử (xác định bằng phương pháp đo độ nhớt) của glucomannan đã được xác định. Kết quả cho thấy, hàm lượng glucomannan trong củ nưa là $4 \%$, khối lượng phân tử đạt khoảng $1,2.10^{6} \mathrm{Da}$, có câu trúc vô định hình và được cấu tạo từ các đơn vị cấu trúc là mannozơ và glucozơ với tỉ lệ tương ứng là $1,00 / 0,13$.

Tù khoá: Nưa thái (Amorphophallus panomensis), glucomannan, konjac. 